\title{
Diagnostic Accuracy and Interpretation of Urine Drug Testing for Pain Patients: An Evidence-Based Approach
}

\author{
Amadeo Pesce ${ }^{1}$, Cameron West ${ }^{1}$, Kathy Egan-City ${ }^{1}$ and William Clarke ${ }^{2}$ \\ ${ }^{1}$ Millennium Research Institute, \\ 2Johns Hopkins School of Medicine, \\ USA
}

\section{Introduction}

Pain is a complex disease. The complexities and co-morbidities of this disease include depression, anxiety, addiction, and other psychological diagnoses that lead to difficulties in management and aberrant behavior such as not taking medications as prescribed, taking additional medications, or illicit drugs. In the effort to provide the highest standard of care for their patients, pain physicians are required to continually assess patients for addiction and, if necessary, refer them to addictionologists for additional treatment (Chou et al., 2009).

\subsection{Chronic opioid therapy}

In this chapter we will refer to pain patients as those persons being treated with chronic opioid therapy for non-cancer-related pain. It is this patient population that has been associated with opiate abuse and diversion, and therefore monitoring these patients for drug use in a manner analogous to therapeutic drug monitoring is necessary. One of the most frequent complaints by patients seeing pain physicians is back pain, which is often associated with failed back surgery (Manchikanti et al., 2004; Michna et al., 2007). Currently opiate medications are one of the treatments of choice used by physicians to provide pain relief. These medications can induce euphoria as well as pain relief; because of this, opiates are frequently abused by this population, as well as the general population (National Survey on Drug Use and Health: Detailed Tables - Prevalence Estimates, Standard Errors, P Values, and Sample Sizes, 1995-2006; Webster \& Dove, 2007). Additionally, these medications are associated with physical as well as psychological dependence and can pose addiction risks (Webster \& Dove, 2007).

\subsection{Pain treatment}

One of the treatments of choice for chronic pain involves strong medications such as opioids, as well as additional or adjuvant medications (Chou et al., 2009; Trescot et al., 2006). Side effects of opioids include sedation, dizziness, nausea, vomiting, and constipation. Living day to day with any or all of these symptoms is challenging at the least and is compounded by the underlying pain these patients suffer from. Naturally, patients often 
attempt to minimize the side effects by taking less of the medication when side effects are particularly debilitating or unpleasant. "Chronic pain patients often adjust their dose of prescribed medication in response to changing levels of activity with no malicious or maladaptive intent. Although they may state that their pattern of use of medications is stable, this is often a statement made "on average" rather than a precise pattern of use. This is particularly evident with short-acting medications used in the treatment of breakthrough pain." (Gourlay \& Heit, 2010b)

UDT is used to give confidence to both the physician and the patient that the patient is following the medication regimen and is therefore getting the most benefit from their treatment. In addition, the side effects of these medications often result in their misuse, underuse, and/or mixing of medications that are not prescribed (Manchikanti et al., 2004). This can also result in the social problems of abuse, misuse, or diversion of these medications. These factors require of pain physicians that they be particularly attentive to their prescribing practices. Adding to the complexity of managing pain patients is the fact that these medications are controlled substances and cannot be purchased over the counter, and so have high street value (Katz et al., 2003; National Prescription Drug Threat Assesment, 2009). This in turn requires of the physician that he or she determine whether patients under their care are compliant with their medication regime, binging on their medications, or diverting them for financial gain (Manchikanti et al., 2005, 2006a, 2006b).

\subsection{Complications of pain treatment}

Further compounding the situation, alcohol use is of major concern to the physician because alcohol-drug interactions can cause morbidity (Harmful Interactions: Mixing Alcohol with Medicines, 2007). Although physicians prohibit patient alcohol use during treatment with opiates or benzodiazepines, verbal contracts are commonly broken and therefore alcohol use must be monitored with (UDT) to manage the high risk of alcohol-drug reactions and mortality (Chou et al., 2009; Trescot et al., 2006). In addition, for reasons involving inadequate pain control, sleep deprivation, and psychological pathology, this patient population commonly takes other medications not prescribed by treating physicians as well as illicit drugs (Manchikanti et al., 2005, 2006a, 2006b). To respond to these potential problems, physicians traditionally relied upon behavioral assessment and pill counts to aid them in making treatment decisions. UDT has augmented these tools by providing physicians with objective, scientifically measurable outcomes to help them make decisions (Gourlay et al., 2010; Hammett-Stabler \& Webster, 2008; Nafziger \& Bertino, 2009; Reisfield et al., 2007). A detailed protocol of how to appropriately prescribe these controlled substances for this population is discussed in the book Universal Precautions, by Gourlay and Heit (Gourlay et al., 2005).

\section{Urine drug testing}

Traditionally, UDT has been associated with forensic testing, often referred to as workplace testing, to detect illicit drug use in employees. Workplace UDT has traditionally focused on identifying use of abused drugs including amphetamines (methamphetamine), cocaine, marijuana, phencyclidine (PCP), and heroin (opiates) (Federal Register - Mandatory Guidelines and Proposed Revisions to Mandatory Guidelines for Federal Workplace Drug Testing Programs [Federal Register], 2004). This type of testing is oriented toward determining positive results; that is, identifying the presence of an illicit substance. The 
reasoning behind this focus is obvious; a positive result for a prohibited substance is a cause for a consequence such as job dismissal (Federal Register, 2004). Testing for these drugs usually follows scheduled guidelines established by the Substance Abuse and Mental Health Services Administration (SAMHSA) (Federal Register, 2004). Analytically, the testing involves qualitative immunoassay screening followed by confirmation by mass spectrometry. Testing for patients on chronic opioid therapy is a different paradigm as both positive and negative results are important. It also requires assays that are more sensitive and can determine both the parent drug and one or more of its metabolites.

\subsection{Immunoassays}

Immunoassays are tests that are based on the ability of an antibody to bind with a drug (Feldkamp, 2010). Antibodies are made in such a way that they bind with a specific drug, such as morphine. In one approach, manufacturers of point of care (POC) devices embed test strips with antibodies and install them in devices designed to interact with urine specimens (Amedica Drug Screen Test Cup). A urine specimen with the drug in it (in this example, morphine) will displace the drug-indicator molecule on the test strip causing the morphine drug indicator line to disappear or change color. These test strips are then visually inspected by the person administering the test. The absence or presence of a line or the change in color, such as on a home pregnancy test, indicates whether the result is positive or negative. The immunoassay antibody binding reaction can be measured in other, more sophisticated ways than using test strips, such as reference laboratory analytical instruments (Olympus Au640 Product Information; Siemens V-Twin Analyzer Product Information; Thermo Fisher Mgc-240 Analyzer Product Information). However, the fundamental property of immunoassays is always the binding reaction of the antibody to the test drug (analyte).

\subsection{Limitations of immunoassay}

The qualitative immunoassay model of testing is only a partial UDT solution for the pain population (Gourlay et al., 2010; Hammett-Stabler \& Webster, 2008; Nafziger \& Bertino, 2009; Reisfield et al., 2007). There are a number of reasons for this. First, doctors treating patients for pain are concerned with negative as well as positive results. This is because a negative result can mean that a patient is not taking a prescribed medication. Second, workplace UDT assays do not fit the clinical medication regimen used in the treatment of pain patients and do not take into account the variable dosing often employed by pain patients as they try to balance their need for pain relief against the side effects of these medications (Gourlay \& Heit, 2010a). In analytical terms this means that the cutoff for detection and quantitation (concentration of drug present) must be low enough to capture minimal use of the drug. Thirdly, the physicians need to have an exact indication of the medications the patients are taking. For example, a positive opiate test does not indicate whether the patient is on codeine, hydrocodone, morphine, or hydromorphone. That is, it measures the class not the particular drug. Each of these are specific medications the physician may choose to treat the patient with, so in order to establish compliance it is necessary to determine exactly which medication has been ingested and assure the patient is not taking additional opiates which could create an unsafe situation (Cone et al., 2008). Finally, if an immunoassay screening method is used, the antibody must detect all drugs of that particular class. Recent advances in designing opiate and benzodiazepine classes of drugs have resulted in agents which do not react well with the traditional antibodies. and 
are used in much lower concentrations than the earlier-designed drugs (Fraser, 2001). This complicates identification of these new agents by immunoassay.

\section{Drugs observed in pain patients}

Table 1 lists both licit and illicit drugs as well as alcohol and the frequency observed in the pain patient population tested by Millennium Laboratories. These observations are similar to those reported by Cone (Cone et al., 2008). The medications most commonly found in the urine of this population are clearly hydrocodone and oxycodone, followed by morphine and hydromorphone; codeine is not frequently prescribed for this population. Benzodiazepines are the next most prescribed group. Other opioid medications such as fentanyl, meperidine, tramadol, and propoxyphene are less frequently used. Use of the muscle relaxants carisoprodol is commonly seen. Marijuana is by far the most prevalent among the illicit drugs, followed by cocaine and methamphetamine. From the table it is clear that alcohol use is about $10 \%$ as measured by the presence of alcohol's metabolites ethyl glucuronide (EtG) and ethyl sulfate (EtS) (Crews et al., 2011a; Dahl et al., 2002; Helander \& Beck, 2005; Helander et al., 1996; Schmitt et al., 1997; Stephanson et al., 2002; Wojcik \& Hawthorne, 2007; Wurst et al., 2006; Wurst et al., 2004). These data show that in order to provide appropriate monitoring and decrease risk and mortality for this population, a broad test menu is needed. These same drugs are often abused and frequently found to be present though they had not been prescribed by the treating physician. Table 2 shows the frequency of these nonprescribed drugs in the pain patient population.

\subsection{Need for urine drug testing}

Many physicians prescribing opioids for non-cancer pain patients follow guidelines established by the American Pain Society (Chou et al., 2009). These guidelines specify the regular or periodic use of UDT as a component of treatment, including administering UDT upon assessing potential risk for substance abuse, misuse or addiction (Atluri \& Sudarshan, 2003; Ives et al., 2006; Madras et al., 2009). Guidelines also suggest that doctors use UDT to monitor patient adherence to prescribed treatments and further state that periodic UDT is warranted because "the therapeutic benefits of these medications are not static and can be affected by changes in the underlying pain condition, coexisting disease, or in psychological or social circumstances" (Chou et al., 2009). In observation of these recommendations, many physicians use POC devices to obtain a real time, in-office assessment of patient compliance, illicit drug use and possible diversion (Manchikanti et al., 2006b, 2010).

\subsection{Point of care testing}

As mentioned previously, these POC devices are qualitative immunoassays that test for various drug classes as well as a few specific drugs. A typical POC device can measure 12 drugs or drug classes (Amedica Drug Screen Test Cup). The most commonly monitored agents are barbiturates, benzodiazepines, opiates, oxycodone, propoxyphene, methadone, tricyclic antidepressants and the illicit drugs methamphetamine, marijuana, cocaine, methylenedioxymethamphetamine (MDMA), and phencyclidine (PCP). The physicians use these screens to immediately detect adherence to regimen or non-adherence to the prescribed drug therapy. At that point they can elicit a more complete drug history, initiate a conversation assessing the need for additional medications not prescribed, or confront the 
Diagnostic Accuracy and Interpretation

of Urine Drug Testing for Pain Patients: An Evidence-Based Approach

\begin{tabular}{|c|c|c|c|c|c|c|}
\hline \multirow{2}{*}{ Drug Class } & $\mathbf{N}$ & $\%$ & Mean & Median & Range & Cutoff \\
\hline & Positive & Positive & (ng/mL) & (ng/mL) & (ng/mL) & (ng/mL) \\
\hline Alcohol & 10,594 & $10.0 \%$ & & & & \\
\hline Ethyl Glucuronide & 8,602 & $81.2 \%$ & $59,827.9$ & $7,220.1$ & $500.47-5,942,830$ & 500 \\
\hline Ethyl Sulfate & 6,644 & $62.7 \%$ & $18,660.7$ & $3,546.1$ & $500.17-1,565,150$ & 500 \\
\hline Ethanol (Screen) & 2,410 & $22.7 \%$ & $735.1 \mathrm{mg} / \mathrm{dL}$ & $68.6 \mathrm{mg} / \mathrm{dL}$ & $20-151,316 \mathrm{mg} / \mathrm{dL}$ & $20 \mathrm{mg} / \mathrm{dL}$ \\
\hline Total Specimens Tested & 106,014 & & & & & \\
\hline Amphetamines & 7,005 & $4.2 \%$ & & & & \\
\hline Amphetamine & 6,045 & $86.3 \%$ & $8,471.2$ & $2,790.2$ & $100.31-409,816$ & 100 \\
\hline Methamphetamine & 1,178 & $16.8 \%$ & $18,217.8$ & $3,263.8$ & $105.12-453,763$ & 100 \\
\hline MDA & 961 & $13.7 \%$ & $1,771.1$ & 844.5 & $101-416,68.9$ & 100 \\
\hline MDMA & 74 & $1.1 \%$ & $5,328.2$ & $1,260.6$ & $120.14-40,395.3$ & 100 \\
\hline Total Specimens Tested & 167,533 & & & & & \\
\hline Barbiturates & 4,797 & $3.6 \%$ & & & & \\
\hline Barbiturates (Screen) & 4,797 & $100.0 \%$ & 927.8 & 904.0 & $200-15,886$ & 200 \\
\hline Total Specimens Tested & 133,032 & & & & & \\
\hline Benzodiazepines & 60,160 & $35.6 \%$ & & & & \\
\hline$\alpha$-Hydroxyalprazolam & 26,954 & $44.8 \%$ & 479.9 & 177.3 & $20-55,249.1$ & 20 \\
\hline Oxazepam & 18,475 & $30.7 \%$ & $2,036.0$ & 617.4 & $40-203,128$ & 40 \\
\hline 7-Amino-Clonazepam & 16,466 & $27.4 \%$ & 674.6 & 287.0 & $20.01-47,501.7$ & 20 \\
\hline Temazepam & 15,647 & $26.0 \%$ & $5,552.3$ & 851.9 & $50-752,950$ & 50 \\
\hline Nordiazepam & 12,758 & $21.2 \%$ & 693.9 & 281.5 & $40-25,864.3$ & 40 \\
\hline Lorazepam & 6,390 & $10.6 \%$ & $1,583.1$ & 681.2 & $40.09-63,170.8$ & 40 \\
\hline Total Specimens Tested & 168,980 & & & & & \\
\hline Buprenorphine & 6,308 & $6.0 \%$ & & & & \\
\hline Buprenorphine & 5,841 & $92.6 \%$ & 313.0 & 75.1 & $10.01-58,691.5$ & 10 \\
\hline Norbuprenorphine & 4,237 & $67.2 \%$ & 639.8 & 279.0 & $20-13,615.1$ & 20 \\
\hline Total Specimens Tested & 104,972 & & & & & \\
\hline Cannabinoids & 11,752 & $11.3 \%$ & & & & \\
\hline cTHC & 11,752 & $100.0 \%$ & 579.6 & 153.1 & $15-25,960.3$ & 15 \\
\hline Total Specimens Tested & 104,453 & & & & & \\
\hline Carisoprodol & 13,302 & $16.4 \%$ & & & & \\
\hline Meprobamate & 13,188 & $99.1 \%$ & $36,884.0$ & $16,190.5$ & $100.18-1,244,200$ & 100 \\
\hline Carisoprodol & 5,379 & $40.4 \%$ & 2,931.9 & 455.0 & 100.1 - 648,442 & 100 \\
\hline Total Specimens Tested & 80,990 & & & & & \\
\hline Cocaine & 4,951 & $3.0 \%$ & & & & \\
\hline Cocaine metabolite & 4,951 & $100.0 \%$ & $12,372.5$ & 627.1 & $50.05-342,160$ & 50 \\
\hline Total Specimens Tested & 166,501 & & & & & \\
\hline
\end{tabular}

Table 1. Drug and Metabolite Prevalence, Positivity, and Concentrations. $N=184,049$ patient specimens. Test dates: 10/01/09-4/29/10. 


\begin{tabular}{|c|c|c|c|c|c|c|}
\hline \multirow{2}{*}{ Drug Class } & $\mathbf{N}$ & $\%$ & Mean & Median & Range & Cutoff \\
\hline & Positive & Positive & (ng/mL) & (ng/mL) & (ng/mL) & (ng/mL) \\
\hline Fentanyl & 13,141 & $14.1 \%$ & & & & \\
\hline Norfentanyl & 11,589 & $88.2 \%$ & 626.8 & 236.6 & $8-47,354.9$ & 8 \\
\hline Fentanyl & 9,283 & $70.6 \%$ & 109.4 & 36.1 & $2-33,050.7$ & 2 \\
\hline Total Specimens Tested & 93,526 & & & & & \\
\hline Meperidine & 6,310 & $7.3 \%$ & & & & \\
\hline Normeperidine & 4,247 & $67.3 \%$ & $1,456.3$ & 339.5 & $50-276,993$ & 50 \\
\hline Meperidine & 2,522 & $40.0 \%$ & $34,321.8$ & $13,533.4$ & $50.18-616,862$ & 50 \\
\hline Total Specimens Tested & 86,344 & & & & & \\
\hline Methadone & 12,415 & $11.0 \%$ & & & & \\
\hline EDDP & 12,109 & $97.5 \%$ & $7,871.9$ & $4,117.3$ & $100.05-251,835$ & 100 \\
\hline Methadone & 11,792 & $95.0 \%$ & $5,265.1$ & $2,409.4$ & $100.11-260,433$ & 100 \\
\hline Total Specimens Tested & 113,073 & & & & & \\
\hline Opiates & 116,683 & $64.6 \%$ & & & & \\
\hline Hydrocodone & 59,346 & $50.9 \%$ & $2,564.4$ & 859.9 & $50-477,876$ & 50 \\
\hline Hydromorphone & 51,205 & $43.9 \%$ & 836.0 & 240.4 & $50-204,633$ & 50 \\
\hline Oxymorphone & 49,688 & $42.6 \%$ & $5,760.2$ & 1,298.6 & $50-1,512,220$ & 50 \\
\hline Oxycodone & 41,603 & $35.7 \%$ & $11,207.3$ & $2,124.5$ & $50-5,947,380$ & 50 \\
\hline Morphine & 21,400 & $18.3 \%$ & $29,611.8$ & $9,600.3$ & $50.06-1,995,940$ & 50 \\
\hline Codeine & 3,686 & $3.2 \%$ & $4,752.0$ & 828.4 & $50.01-233,036$ & 50 \\
\hline 6-Acetylmorphine & 465 & $0.4 \%$ & $1,108.8$ & 275.7 & $10.01-24,069.1$ & 10 \\
\hline Total Specimens Tested & 180,487 & & & & & \\
\hline Phencyclidine & 23 & $0.02 \%$ & & & & \\
\hline Phencyclidine & 23 & $100.0 \%$ & 539.4 & 87.5 & $10.89-3,718.53$ & 10 \\
\hline Total Specimens Tested & 104,137 & & & & & \\
\hline Propoxyphene & 6,397 & $4.8 \%$ & & & & \\
\hline Norpropoxyphene & 6,395 & $100.0 \%$ & $5,524.3$ & $2,026.9$ & $100-167,037$ & 100 \\
\hline Propoxyphene & 2,780 & $43.5 \%$ & $1,919.5$ & 583.6 & $100-178,006$ & 100 \\
\hline Total Specimens Tested & 133,992 & & & & & \\
\hline Tapentadol & 277 & $0.4 \%$ & & & & \\
\hline Tapentadol & 277 & $100.0 \%$ & $11,557.1$ & $6,870.3$ & $52.05-492,895$ & 50 \\
\hline Total Specimens Tested & 66,797 & & & & & \\
\hline Tramadol & 6,521 & $12.1 \%$ & & & & \\
\hline Tramadol & 6,521 & $100.0 \%$ & $19,288.0$ & $8,191.4$ & $100-601,928$ & 100 \\
\hline Total Specimens Tested & 54,111 & & & & & \\
\hline
\end{tabular}

Table 1. (continued). Drug and Metabolite Prevalence, Positivity, and Concentrations. $\mathrm{N}=$ 184,049 patient specimens. Test dates: 10/01/09-4/29/10. 


\begin{tabular}{|c|c|c|}
\hline DRUG CATEGORY & OCCURRENCES & $\%$ of TOTAL \\
\hline Benzodiazepine & 14,559 & $28.32 \%$ \\
\hline Illicit Drugs & 6,769 & $13.17 \%$ \\
\hline Natural and Semi-Synthetic Opioids & 13,241 & $25.75 \%$ \\
\hline Other & 11,514 & $22.39 \%$ \\
\hline Stimulants & 954 & $1.86 \%$ \\
\hline Synthetic Opioids & 4,379 & $8.52 \%$ \\
\hline TOTALS & 51,416 & $100.00 \%$ \\
\hline Total Creatinine Tests & 69,888 & \\
\hline Total RADAR C Positives & 51,416 & \\
\hline$\%$ POSITIVE & $73.57 \%$ & \\
\hline Benzodiazepine & 14,559 & \\
\hline 7-Amino-Clonazepam & 3,864 & \\
\hline Alpha-Hydroxyalprazolam & 5,543 & \\
\hline Lorazepam & 1,079 & \\
\hline Nordiazepam & 1,907 & \\
\hline Oxazepam & 1,803 & \\
\hline Temazepam & 363 & \\
\hline Illicit Drugs & 6,769 & \\
\hline 6-MAM (Heroin metabolite) & 165 & \\
\hline Cocaine metabolite & 1,710 & \\
\hline Methamphetamine & 320 & \\
\hline MDMA & 17 & \\
\hline cTHC (Marijuana metabolite) & 4,546 & \\
\hline Phencyclidine & 11 & \\
\hline Natural and Semi-Synthetic Opioids & 13,241 & \\
\hline Buprenorphine & 809 & \\
\hline Codeine & 692 & \\
\hline Hydrocodone & 5,138 & \\
\hline Hydromorphone & 1,789 & \\
\hline Morphine & 1,317 & \\
\hline Norbuprenorphine & 73 & \\
\hline Oxycodone & 2,618 & \\
\hline Oxymorphone & 805 & \\
\hline Other & 11,514 & \\
\hline Carisoprodol & 735 & \\
\hline Ethyl Glucuronide & 5,320 & \\
\hline Ethyl Sulfate & 4,820 & \\
\hline Meprobamate & 639 & \\
\hline Stimulants & 954 & \\
\hline Amphetamine & 954 & \\
\hline Synthetic Opioids & 4,379 & \\
\hline EDDP (Methadone metabolite) & 1,381 & \\
\hline Fentanyl & 729 & \\
\hline Meperidine & 29 & \\
\hline Methadone & 271 & \\
\hline Norfentanyl & 204 & \\
\hline Normeperidine & 55 & \\
\hline Norpropoxyphene & 898 & \\
\hline Propoxyphene & 25 & \\
\hline Tapentadol & 17 & \\
\hline Tramadol & 770 & \\
\hline
\end{tabular}

Table 2. Incidence of Non-prescribed Use of Prescription Medications and Illicit Drugs. 
patient about illicit drug use. Point of care devices are extremely useful because they provide physicians with immediate information, particularly on initial patient intake. Of course, like many CLIA-waived (or simple) test devices, they do have limitations, inasmuch as they require that a person visually inspect them in order to interpret the results. For this reason as well as the fact that these units are not $100 \%$ accurate, manufacturers of POC devices recommend that doctors not confront patients without first confirming the POC results (Table 3) (Amedica Drug Screen Test Cup). Table 3 lists a number of known drugs or agents that cause false positive results in POC immunoassays. In contrast with POC immunoassay tests, which only show a positive or negative result, laboratory-based immunoassays are often semi-quantitative (Feldkamp, 2010). This means that a positive result for morphine will also indicate approximately how much morphine is in the specimen. These immunoassays have quality control and proficiency testing surveys that make the results more objective and reliable than those obtained using POC devices (American Proficiency Institute 2011 Catalog of Programs, 2011; College of American Pathologists 2011 Surveys and Anatomic Pathology Education Programs, 2011).

\begin{tabular}{|c|c|c|c|}
\hline $\begin{array}{c}\text { POCT Kit } \\
\text { Abbreviation }\end{array}$ & \begin{tabular}{|c|} 
Drug or Drug \\
Class
\end{tabular} & Target Drugs ${ }^{1}$ & $\begin{array}{l}\text { Compounds That May } \\
\text { Cause A False Positive }^{1}\end{array}$ \\
\hline THC & Marijuana & $\begin{array}{l}\text { Marijuana and Marinol } \\
\text { (contains THC), }\end{array}$ & $\begin{array}{l}\text { Prilosec, Protonix, } \\
\text { efavirenz, NSAIDs }\end{array}$ \\
\hline $\mathrm{COC}$ & Cocaine & Cocaine & Unknown/Infrequent \\
\hline OPI300² & Opiates & $\begin{array}{l}\text { Codeine, morphine, } \\
\text { hydrocodone, } \\
\text { hydromorphone. Also, poppy } \\
\text { seeds that contain morphine. }\end{array}$ & Oxycodone \\
\hline AMP & $\begin{array}{l}\text { Ampheta- } \\
\text { mines }\end{array}$ & $\begin{array}{l}\text { Amphetamine, Adderall. } \\
\text { Occasionally: benzphetamine, } \\
\text { selegiline, Vicks Nasal Inhaler }\end{array}$ & $\begin{array}{l}\text { Phenylpropanolamine, } \\
\text { ephedrine, } \\
\text { pseudoephedrine, } \\
\text { ranitidine, } \\
\text { phentermine }\end{array}$ \\
\hline MET & $\begin{array}{l}\text { Methampheta- } \\
\text { mine }\end{array}$ & $\begin{array}{l}\text { Methamphetamine. } \\
\text { Occasionally: benzphetamine, } \\
\text { selegilene, Vicks Nasal } \\
\text { Inhaler }{ }^{4}\end{array}$ & $\begin{array}{l}\text { Adderal, } \\
\text { phenylpropanolamine, } \\
\text { ephedrine, } \\
\text { pseudoephedrine, } \\
\text { ranitidine, phentermine }\end{array}$ \\
\hline PCP & Phencyclidine & Phencyclidine & $\begin{array}{l}\text { Venlafaxine, } \\
\text { dextromethorphan, } \\
\text { diphenhydramine } \\
\end{array}$ \\
\hline MDMA & $\begin{array}{l}\text { Methylene- } \\
\text { dioxymetham } \\
\text { phetamine }\end{array}$ & $\begin{array}{l}\text { Methylenedioxy- } \\
\text { methamphetamine }\end{array}$ & $\begin{array}{l}\text { Phenylpropanolamine, } \\
\text { ephedrine, } \\
\text { pseudoephedrine, } \\
\text { ranitidine, phentermine }\end{array}$ \\
\hline BAR & Barbiturates & $\begin{array}{l}\text { Butalbital, phenobarbital, } \\
\text { secobarbital, amobarbital and } \\
\text { other barbiturates }\end{array}$ & Unknown/Infrequent \\
\hline
\end{tabular}




\begin{tabular}{|c|c|l|l|}
\hline BZO & $\begin{array}{c}\text { Benzodiaze- } \\
\text { pines }\end{array}$ & $\begin{array}{l}\text { Oxazepam, nordiazepam, } \\
\text { temazepam, alprazolam and } \\
\text { other benzodiazepines to } \\
\text { varying degrees }\end{array}$ & Oxaprozin, sertaline \\
\hline MTD & Methadone & Methadone & Verapamil, quetiapine \\
\hline TCA & $\begin{array}{c}\text { Tricyclic } \\
\text { Antidepres- } \\
\text { sants }\end{array}$ & $\begin{array}{l}\text { Amitriptyline, nortriptyline, } \\
\text { imipramine, desipramine, } \\
\text { doxepin and other tricyclics to } \\
\text { varying degrees. }\end{array}$ & $\begin{array}{l}\text { Cyclobenzaprine, } \\
\text { carbamazepine, } \\
\text { diphenhydramine }\end{array}$ \\
\hline OXY $^{3}$ & Oxycodone & Oxycodone and oxymorphone & $\begin{array}{l}\text { Codeine, morphine, } \\
\text { hydrocodone and } \\
\text { hydromorphone }\end{array}$ \\
\hline
\end{tabular}

Table 3. False Positive Results: Immunoassay Cross Reactants.

${ }^{1}$ While most immunoassays are highly selective for their target compounds, cross reactive compounds and adulterants, particularly when present at high concentrations may result in a false positive. Additional cross reactants have been reported and cross reactivity may vary between immunoassay manufacturers and lot to lot. The manufacturers of point of care test devices recommend that positive results should be confirmed by mass spectrometry.

${ }^{2}$ OPI300 is an assay to detect codeine, morphine, hydrocodone and hydromorphone. Oxycodone may give a positive at higher concentrations.

${ }^{3} \mathrm{OXY}$ is an assay to detect Oxycodone. Other opiates, esp. codeine, morphine, hydrocodone and hydromorphone may give a positive result at higher concentrations.

${ }^{4}$ Adderall contains amphetamine. Benzphetamine (Didrex) is metabolized to d-amphetamine and dmethamphetamine. Selegiline (Eldepryl) is metabolized to l-amphetamine and l-methamphetamine.

Vick's Inhaler contains l-methamphetamine.

\subsection{Determining appropriate UDT cutoffs}

Sensitivity of detection currently used in many immunoassays may not be appropriate for the pain patient. This is because manufacturers set cutoffs for assays to identify overdose in emergency unit settings (Fraser \& Zamecnik, 2003; Fraser, 2001; Hattab et al., 2000; Wingert, 1997). There is a need to establish appropriate cutoffs for patients on clinical doses of their medications rather than the high concentrations encountered in overdose situations. Specifically, studies have been conducted that better identify the appropriate cutoff for the pain patient population (Pesce et al., 2011).

One definition of appropriate cutoff levels is one that captures $97.5 \%$ or more of the population on a specific drug (Pesce et al., 2011). An example of the importance of setting appropriate cutoffs is for the drug clonazepam (West et al., 2010b). When measured by immunoassay using a nominal cutoff of $200 \mathrm{ng} / \mathrm{mL}$, only $28 \%$ of the patients on the drug were determined to be compliant. When the same samples were measured by LC-MS/MS technique using a cutoff of $200 \mathrm{ng} / \mathrm{mL}$, the group was found to be $70 \%$ compliant. Finally, when the LC-MS/MS cutoff was lowered to $40 \mathrm{ng} / \mathrm{mL}$ the group was $87 \%$ compliant. This study showed that first the immunoassay was insensitive in that the nominal $200 \mathrm{ng} / \mathrm{mL}$ cutoff did not apply to clonazepam, and second, a lower cutoff was needed to appropriately categorize compliance. Other studies have shown the need for lower cutoffs for pain medications (Mikel et al., 2009; Pesce et al., 2010a). As the consequences to the patient of dismissal from a practice can be very large and even life-changing (e.g., loss of insurance, loss of job or income), it is essential that physicians do not unjustifiably dismiss even a 
single patient who is compliant with their medication regimens. This can be avoided by using appropriate cutoffs.

In an attempt to better define appropriate cutoffs for the pain patient population, the quantitative urine drug test results were examined for the prescription medications listed in Table 4. Using the criterion that the cutoffs should capture $97.5 \%$ of the examined population and employing the LC-MS/MS cutoffs listed in Table 4 showed it was possible to meet this standard (Pesce et al., 2011). One limitation of this approach is that the time after last dose and the dose itself were not known for these subjects. Regardless of the limitations of the study, the lower cutoffs provide results that can clearly identify compliance more accurately than other methods.

\begin{tabular}{|c|c|c|c|}
\hline \multirow[b]{2}{*}{ Drug } & \multirow{2}{*}{$\begin{array}{c}\text { Analytical } \\
\text { Cutoff }(\mathrm{ng} / \mathrm{mL})\end{array}$} & \multicolumn{2}{|c|}{ Lower $2.5 \%$} \\
\hline & & \begin{tabular}{|c|} 
Estimated New \\
Cutoff (Raw, ng/mL)
\end{tabular} & \begin{tabular}{|c} 
CR Normalized Cutoff \\
$(\mu \mathrm{g} / \mathrm{g}$ creatinine $)$
\end{tabular} \\
\hline 7-Amino-Clonazepam & 10 & 19 & 15 \\
\hline Alpha-Hydroxyalprazolam & 10 & 15 & 11 \\
\hline Amphetamine & 50 & 76 & 59 \\
\hline Buprenorphine & 5 & 7 & 5 \\
\hline Carisoprodol & 50 & 56 & 35 \\
\hline Codeine & 25 & 29 & 15 \\
\hline Fentanyl & 1 & 2 & 2 \\
\hline Hydrocodone & 25 & 41 & 31 \\
\hline Hydromorphone & 25 & 34 & 26 \\
\hline Lorazepam & 20 & 30 & 25 \\
\hline Meperidine & 25 & 88 & 28 \\
\hline Meprobamate & 50 & 92 & 113 \\
\hline Methadone & 50 & 89 & 74 \\
\hline Morphine & 25 & 59 & 52 \\
\hline Oxycodone & 25 & 45 & 46 \\
\hline Oxymorphone & 25 & 44 & 38 \\
\hline Propoxyphene & 50 & 60 & 42 \\
\hline Tapentadol & 25 & 42 & 58 \\
\hline Tramadol & 50 & 147 & 70 \\
\hline
\end{tabular}

Table 4. Medication Cutoff Values. Modified with permission from Pesce et al., 2011.

As stated earlier, illicit drug use is common in this population (Madras et al., 2009; Schuckman et al., 2008). It stands to reason that identifying the appropriate illicit drug cutoffs for UDT is equally important. Using the same criterion as stated above, cutoffs for marijuana, cocaine, and methamphetamine have also been determined (Table 5) (West et al., 2011a). The lowering of these illicit drug cutoffs consistent with the latest SAMHSA guidelines in which the cocaine and amphetamine cutoffs were lowered to capture more illicit drug users (Federal Register, 2004). 


\begin{tabular}{|l|c|c|}
\hline \multirow{2}{*}{ Drug } & \multicolumn{2}{|c|}{ Lower 2.5\% } \\
\cline { 2 - 3 } & $\begin{array}{c}\text { Raw } \\
\text { (ng/mL) }\end{array}$ & $\begin{array}{c}\text { CR Normalized } \\
\text { (ng/mg CR) }\end{array}$ \\
\hline Cocaine & 29.6 & 17 \\
\hline Marijuana & 9.5 & 6.2 \\
\hline Methamphetamine & 56.1 & 33.5 \\
\hline
\end{tabular}

Table 5. Illicit Drug Cutoff Values. Modified with permission from West et al., 2011a.

\subsection{Confirmatory testing: mass spectrometry}

Physicians dealing with pain patients not following the treatment plan or using illicit or non-prescribed medications, have difficulty with these situations (Jung \& Reidenberg, 2007). The doctor must be absolutely confident that the test data from both the POC and laboratory conducting further testing is correct. By having positive results obtained in their offices as well as confirmatory laboratory data, physicians can confidently discuss expectations and behavioral changes with patients. Questions about laboratory mix-up of specimens or laboratory error can be dismissed.

Many laboratories performing UDT on the pain patient population typically test specimens by immunoassay and then follow this with confirmation by mass spectrometry (Cone et al., 2008). Mass spectrometry is an analytical technique that separates molecules based on their weight (mass) and fragmentation pattern. Identification is based on the fact that each drug has a specific mass and breakdown in the same way that each person has a specific fingerprint. A mass spectrometry instrument is usually coupled to a chromatographic column, in which the test drug, for example morphine, is separated from other components in the urine before submitting the sample into the mass spectrometer. The mass spectrometer identifies the test drug by its position in the chromatogram, the specific weight of the molecule, and by its fragmentation pattern. This technology is virtually foolproof. Mass spectrometry techniques are divided into two methods: gas chromatography-mass spectrometry (GC-MS) and liquid chromatography-tandem mass spectrometry (LCMS/MS). Of the two, the newer LC-MS/MS is considered the gold standard, for reasons we will describe later (Siuzdak, 2006).

In cases where the physician wants the results immediately (within hours), confirmatory mass-spectrometry methods used at the most modern diagnostic laboratories provide results within 24-30 hours. As stated above, the major limitations of immunoassays are inappropriate cutoffs (sensitivity), varying specificity for individual drugs, and crossreactivity with other agents producing both false-negative and false-positive results (Manchikanti et al., 2008). The term cross reactivity is used to describe the reaction of an antibody with a chemical that is not the original immunizing drug. The reaction is poor because the affinity is much worse than the original drug. By poor we mean that at the same concentration of the original drug the test compound does not bind as well. However, as the concentration of the test compound is increased it eventually saturates the antibody binding site giving a positive test result.

\subsection{Test menu requirement}

As mentioned earlier a broader clinical laboratory UDT menu is necessary to accurately monitor the pain patient population. Smaller hospitals as well as physician offices cannot 
meet this requirement. One reason for this is that immunoassays require separate analytical channels for each assay and this limits the number of tests a smaller laboratory may have in its menu (Olympus Au640 Product Information; Siemens V-Twin Analyzer Product Information; Thermo Fisher Mgc-240 Analyzer Product Information). Another reason is that certain drug tests may not exist for the laboratory's specific instruments, and the addition of another instrument is financially prohibitive, particularly if that instrument is a mass spectrometer (Agilent Technologies, Inc.). Many physicians treating the pain patient population send specimens to reference laboratories specifically designed to provide the required test menu to meet these needs. Tests for new drugs (i.e., tapentadol) (Nucynta - Tapentadol, 2010) or new illicit substances (i.e., K2, spice) (Sobolevsky et al., 2010; Vardakou et al., 2010) encountered in the pain patient population can be rapidly set up and validated on LC-MS/MS instrumentation. Therefore, this analytical technique is supplementing screening by immunoassay. Because of the limitations of immunoassays, confirmatory testing is essential for accurate clinical assessment of medication usage. With confirmatory testing, physicians have specific evidence of what medications a patient is or isn't taking. This assures the doctor that he or she is not discharging a patient inappropriately, and that care is appropriate and not limited.. The laboratories with the most advanced technology can eliminate the immunoassay step saving both the patient and the insurer money.

\subsection{Mass spectrometry as the gold standard for testing}

At this point in time, mass spectrometry is considered the method of choice for UDT analysis in pain management. This is because mass spectrometry offers the chromatographic separation and mass fragmentation patterns that are specific for the test medications such as opiates and benzodiazepines (Mohsin et al., 2007). In addition, this analytic approach uses isotope dilution to quantify the amount of drug in the urine specimen; isotope dilution is considered the gold standard for determining how much of a drug is in a specimen (quantitation) (Federal Register, 2004). This ability to quantify the amount of drug in urine has been proposed as a method of detecting drug abuse (Pesce et al., 2010c). However, it is important to note that it is not possible to relate the quantitative excretion of a drug to the drug dosage (Nafziger \& Bertino, 2009). Quantitation of drugs using immunoassay technology is problematic, particularly if the antibody reagent cross reacts with multiple structurally related drugs; if the urine drug sample contains more than one drug in a class (i.e., hydrocodone and hydromorphone), the antibody reaction will vary with each drug present in the solution. This means that the assay cannot distinguish between the two drugs and give a reliable calculation of the amount of either drug present (Feldkamp, 2010).

Of the two commonly used mass spectrometry methods, LC-MS/MS offers several advantages over GC-MS (Mikel et al., 2010). These include the ability to discriminate a larger number of drugs in each test run, the very small amount of urine specimen required (as little as 25 microliters, or one drop), and the ability to use a sample that is neither derivatized nor extracted. This in turn has made possible the analysis of hundreds of urine specimens per day for a single mass spectrometer. Advances in the automated handling of specimens and bar coding allow for the accurate processing of thousands of samples per day. This method of analysis can provide physicians with results more rapidly than by GCMS (Mikel et al., 2010). 


\section{Interpretation of UDT results}

The accurate interpretation of test results requires an understanding of the usefulness and limitations of immunoassays (Gourlay et al., 2010; Hammett-Stabler \& Webster, 2008; Manchikanti et al., 2010; Nafziger \& Bertino, 2009; Reisfield et al., 2007), a knowledge of opiate metabolism, and awareness of the expected ratios of the parent drug and its metabolites in urine (Reisfield et al., 2007). In addition, small amount of impurities in medications detectable by mass spectrometry can complicate the interpretation of UDT results. For example, codeine is present in morphine preparations and hydrocodone is present in oxycodone preparations (Evans et al., 2009; West et al., 2009, 2011b). Physicians who aren't aware of the presence of these impurities may wrongly dismiss a patient because he or she tested positive for codeine or hydrocodone when it was not prescribed. The presence of both parent drug and its metabolite in a urine sample readily measured by mass spectrometry can reassure the physician that the patient is taking the medication and that it is being metabolized appropriately. Also, for some drugs such as carisoprodol, fentanyl, or buprenorphine, only the metabolite may be observed. It is imperative that physicians prescribing these medications use a reference laboratory that is able to measure both the parent drug and its corresponding metabolite and be able to present interpretive results for the physician (Heltsley et al., 2010). Creatinine is a metabolic breakdown product that is present in urine. The amount of creatinine excreted into urine is nearly constant for any individual. Reference laboratories calculate the amount of drug excreted per gram of creatinine, which allows the monitoring of excreted medication or illicit drug over time. This information is useful to physicians in certain circumstances because some drugs, such as nordiazepam remain in the system long after a person stops taking them. A UDT result that is not corrected for creatinine may show that the patient is more positive for the drug than on a previous test, even though the patient has in fact stopped taking it. Except for changes in the patient's renal status, or loss from adipose tissue due to dieting, this conflicting result may be due to the second urine being more concentrated than the first. A creatinine-corrected value will correct for a patient's hydration on the day of the test and show a decrease in the amount of nordiazepam in the urine, thus supporting the patient's claim that he or she has stopped taking the drug. It is important that reference laboratories not only provide creatininecorrected results but that they give doctors or staff help in interpreting the data (Cone et al., 2009). It is also important for the physician to know if a patient has attempted to obscure UDT results by diluting a urine specimen. To accomplish this, he or she must have a grasp of creatinine and specific gravity UDT validity tests $(\mathrm{Wu}, 2001)$. Laboratory staff who interface with clients should provide this information when questions arise.

\section{Monitoring ethanol use in pain patients}

As stated earlier, alcohol (ethanol) use among pain patients is a significant problem because of the risk for drug-drug interaction with opioid medication. For doctors to understand UDT ethanol results, it is essential that they understand ethanol metabolism and the formation of the ethanol byproducts ethyl glucuronide and ethyl sulfate (Crews et al., 2011a; Crews et al., 2011b; Dahl et al., 2002; Helander \& Beck, 2005; Helander et al., 1996; Rosano \& Lin, 2008; Schmitt et al., 1997; Stephanson et al., 2002; Wojcik \& Hawthorne, 2007; Wurst et al., 2006; Wurst et al., 2004). This is because false positive ethanol results can result from fermentation of glucose from diabetic patient samples (Crews et al., 2011b). Crews et al. reported that about $1 / 3$ of the ethanol positive samples were due to fermentation. Misinterpretation of 
these results can have grave consequences as doctors may establish a contract with a patient that he or she abstain from any alcohol use while being treated with opioid medication; therefore, a positive finding for alcohol use can result in dismissal from the practice (Federal Register, 2004).

\section{When to use UDT}

Urine drug testing must be tailored to fit the pain patient's clinical history. For the intake visit, the patient is advised as to the necessity for UDT and is typically requested to provide a urine specimen. If the patient fails to do this, he or she may be immediately dismissed from the practice. In some practices, the urine specimen is tested by a POC device at the time of the appointment and the results are compared to the patient reported history. If necessary, discrepancies are discussed. As a matter of course, a portion of the POC urine sample is sent to the reference laboratory to confirm the POC test results, test for additional medications, and, at the discretion of the physician, to test for the prescribed medications, non-prescribed medications and illicit drugs at lower cutoff levels than those provided by the POC test.

For many established pain patients, quarterly or semi-annual UDT is considered appropriate. It is best if this is done on a random basis. The strongest recommendation for doing UDT is adding additional medications to the regimen or changing medications. Urine drug testing may also be administered if a patient changes their behavior or exhibits addiction tendencies such as complaining of running out of medications early (Chou et al., 2009; Trescot et al., 2006). Testing may be conducted as frequently as every office visit for some patients who exhibit unusual behavior, have a history of abuse, or if illicit or nonprescription drugs were found to be present on a previous test. Gourlay, D. \& Heit, H. (2010a).

\section{Purposes and costs of UDT}

As stated earlier, the purpose of UDT (as well as the relative costs) may be broken down into three components: testing prescribed medications for compliance; testing for nonprescribed medications; and testing for illicit drugs. At the time when the forensic model of drug testing was instituted the vast majority of people who died from drugs died from the use of illicit drugs. At this point in time more people die from prescription medications than by illicit drugs (Hall et al., 2008; Krausz et al., 1996; Okie, 2010). There are now 13 or more classes of drugs that are used to treat pain. Pain patients are on an average using three of these drugs (Kuehn, 2007; Okie, 2010). Therefore, for every 100 patients, 300 confirmations by mass spectroscopy are required. This is more than a 100-fold increase in the number of tests needed to serve this patient population compared to workplace testing. This represents a radical change in UDT model from the forensic model used at the time when the purpose of drug testing was to root out the one or two percent of drug-using professional drivers. It is important that legislators and payors for UDT services understand the shift from the forensic UDT model to the clinical model. Currently the insurance reimbursement codes and categories do not accurately reflect the costs associated with these new clinical drug testing requirements (Cpt Current Procedural Technology, 2010).

\subsection{Cost effectiveness of UDT}

It is also important to discuss the cost-effectiveness of UDT. The National Institute on Drug Abuse (NIDA) states that the cost of not treating an addict is $\$ 56,000 /$ year. An example of 
effective treatment for heroin addiction is the methadone maintenance program, which has an average cost of $\$ 4,700 /$ per patient/per year (Principles of Drug Addiction Treatment: A Research-Based Guide, 2009). Based on these figures, every dollar invested in drug treatment programs yields a return of about 12 times this amount. The goal then should be detecting untreated drug abuse. Urine drug testing helps accomplish this goal.

There are two aspects of drug abuse in the pain patient population; one is the use of illicit drugs, and the other more prevalent aspect is abuse of the prescribed and non-prescribed medications. Combined, these two facets of abuse may approach $20-30 \%$ of the patients on chronic opioid therapy. Using this percentage of patients and factoring the $\$ 56,000 /$ patient cost, this means that on average each of these patients may actually be costing society and insurers $\$ 16,800$ more annually than what is estimated by only calculating costs of office visits and medications. If clinical UDT is performed 2-4 times per year for each patient reimbursed at $\$ 500$ per UDT, this represents a cost of $\$ 1000-\$ 2000$ per patient per year. This is in contrast to the $\$ 16,800$ referenced above. It seems clear that using UDT to detect these patients should significantly reduce the cost of care as well as the costs to society (Wall et al., 2000).

\subsection{Social costs of drug abuse}

In light of the fact that providing the highest standard of care is one of the basic tenets of the medical profession, it is important to note that several studies have shown that untreated opioid-abusing patients have significantly higher societal cost (Wall et al., 2000) and mortality rate (between 2 and 10 times) than the comparative general population (Hall et al., 2008; Oyefeso et al., 1999). Based on this data alone, the use of UDT should be justified for pain patients.

\section{Conclusions}

\subsection{When and how to test}

Pain is a complex disease and chronic opioid therapy is one of the treatments of choice. Urine drug testing is one of the ways to measure patient adherence to the treatment regimen. At the intake office visit it is important for the physician to be able to make immediate assessment of the patient to validate their reported history and to determine the overt presence of illicit drugs or non-prescribed medications. Either a POC device or inoffice immunoassay analyzer should be used for this purpose. A portion of the patient's urine specimen should be sent to a reference laboratory for analysis using lower cutoffs and a much extended test menu such as those listed in Tables 1 and 2. As stated earlier, this will give the physician further confidence that the patient's history is valid and provide measurable evidence for informed clinical decision making. In addition, alcohol use, which cannot easily be detected by the POC devices, can be identified as a risk factor.

\subsection{Ongoing testing}

At subsequent visits UDT will provide the physician with evidence of patient compliance with prescribed medications (West et al., 2010a) and eliminate the potential for abuse of non-prescribed medications or illicit drugs (Pesce et al., 2010b). For this purpose, depending upon clinical judgment, the test menu does not have to be quite as extensive. Tests for rarely-observed illicit drugs such as MDMA and PCP may not be included. Similarly, tests for rarely-prescribed or removed medications such as propoxyphene may not be included. If intake visit UDT showed that the patient was observed to be taking a non-prescribed 
medication or illicit drug then subsequent visit UDT's should include tests for those agents. Because of the potential for morbidity from alcohol-medication interactions, it may be necessary to continue to monitor certain patients for ethanol and its metabolites.

\subsection{Minimum analytical requirements}

When monitoring for opioid medication compliance, the testing method should be able to differentiate between codeine, morphine, hydrocodone, norhydrocodone, and hydromorphone. The test should also be able to differentiate between oxycodone, noroxycodone, and oxymorphone. This will allow the physician to determine that the opiate the patient is taking is in fact the one being prescribed and that the patient is metabolizing the medication properly (Pesce et al., 2010a). A similar case can be made for the testing of benzodiazepines. The method should be able to detect at low concentrations and

differentiate between alpha-hydroxyalprazolam, 7-aminoclonazepam, lorazepam, nordiazepam, temazepam, and oxazepam. This will allow the doctor to see that the patient is taking the prescribed benzodiazepine and allay any concerns about doctor shopping. Frequency of UDT should be based on the physician's observations of the patient's behavior as well as suggested guidelines. For those patients whose behavior is not of concern, some guidelines suggest UDT between two and four times per year on a random basis (Chou et al., 2009; Trescot et al., 2006). For those patients with non-compliant behavior or a history of addiction, testing should be done as often as every office visit (Chou et al., 2009; Trescot et al., 2006).

\section{References}

Agilent Technologies, Inc. 5301 Stevens Creek Blvd, Santa Clara, CA 95051, USA. Thermo Fisher Scientific. 81 Wyman St, Waltham, MA 02454, USA.

Amedica Drug Screen Test Cup. Hayward, CA: Amedica Biotech, Inc.

American Proficiency Institute 2011 Catalog of Programs. Traverse City, MI: American Proficiency Institute, 2011.

Atluri, S. \& Sudarshan, G. (2003). Evaluation of Abnormal Urine Drug Screens among Patients with Chronic Non-Malignant Pain Treated with Opioids. Pain Physician, Vol.6, No.4, pp.407-409,

Chou, R., Fanciullo, G., Fine, P., Adler, J., Ballantyne, J., Davies, P., Donovan, M., Fishbain, D., Foley, K., Fudin, J., Gilson, A., Kelter, A., Mauskop, A., O'Connor, P., Passik, S., Pasternak, G., Portenoy, R., Rich, B., Roberts, R., Todd, K. \& Miaskowski, C. (2009). Clinical Guidelines for the Use of Chronic Opioid Therapy in Chronic Noncancer Pain. The Journal of Pain, Vol.10, No.2, (February 2009), pp.113-130, 1526-5900

College of American Pathologists 2011 Surveys and Anatomic Pathology Education Programs. Northfield, IL: College of American Pathologists, 2011.

Cone, E., Caplan, Y., Black, D., Robert, T. \& Moser, F. (2008). Urine Drug Testing of Chronic Pain Patients: Licit and Illicit Drug Patterns. Journal of Analytical Toxicology, Vol.32, No.8, (October 2008), pp.530-543, ISSN 1945-2403

Cone, E., Caplan, Y., Moser, F., Robert, T., Shelby, M. \& Black, D. (2009). Normalization of Urinary Drug Concentrations with Specific Gravity and Creatinine. Journal of Analytical Toxicology, Vol.33, No.1, (January-February 2009), pp.1-7, ISSN 1945-2403 
Cpt Current Procedural Technology. (2010). ( Professional ed.), American Medical Association, Chicago, IL

Crews, B., Latyshev, S., Mikel, C., Almazan, P., West, R., Pesce, A. \& West, C. (2011a). Improved Detection of Ethyl Glucuronide and Ethyl Sulfate in a Pain Management Population Using High-Throughput Lc-Ms/Ms. Journal of Opioid Management, Vol.6, No.6, (Novenber-December 2010), pp.415-421, ISSN 1551-7489

Crews, B., West, R., Gutierrez, R., Latyshev, S., Mikel, C., Almazan, P., Pesce, A., West, C. \& Rosenthal, M. (2011b). An Improved Method of Determining Ethanol Use in a Chronic Pain Population. Journal of Opioid Management, Vol.In Press, (n.d.), ISSN 1551-7489

Dahl, H., Stephanson, N., Beck, O. \& Helander, A. (2002). Comparison of Urinary Excretion Characteristics of Ethanol and Ethyl Glucuronide. Journal of Analytical Toxicology, Vol.26, No.4, (May-June 2002), pp.201-204, ISSN 1945-2403

Evans, M., Kriger, S., Gunn, J. \& Schwilke, E. (2009). Anomalous Opiate Detection in Compliance Monitoring. Practical Pain Management, Vol.9, No.7, (September 2009), pp.54-55,

Federal Register - Mandatory Guidelines and Proposed Revisions to Mandatory Guidelines for Federal Workplace Drug Testing Programs. Substance Abuse and Mental Health Services Administration. Rockville, MD: Department of Health and Human Services, 2004;69(71).

Feldkamp, C.S. (2010). Immunological Reactions, In: Clinical Chemistry: Theory, Analysis, and Correlation, L. A. Kaplan and A. J. Pesce, pp. 151-179, Mosby, St. Louis

Fraser, A. \& Zamecnik, J. (2003). Impact of Lowering the Screening and Confirmation Cutoff Values for Urine Drug Testing Based on Dilution Indicators. Therapeutic Drug Monitoring, Vol.25, No.6, (December 2003), pp.723-727, ISSN 1536-3694

Fraser, A.D. (2001). Psychotropic Agents: The Benzodiazepines, In: The Clinical Toxicology Laboratory: Contemporary Practice of Poisoning Evaluation, L. C. Shaw, T. C. Kwong, T. G. Rosano, P. J. Orsolak, B. A. Wolf and B. Magnani, pp. 211-221, American Association for Clinical Chemistry, Inc., Washington, DC

Gourlay, D. \& Heit, H. (2010a). The Art and Science of Urine Drug Testing. The Clinical Journal of Pain, Vol.26, No.4, (May 2010), pp.358, ISSN 0749-8047

Gourlay, D., Heit, H. \& Almahrezi, A. (2005). Universal Precautions in Pain Medicine: A Rational Approach to the Treatment of Chronic Pain. Pain Medicine, Vol.6, No.2, (March-April 2010), pp.107-112, ISSN 1526-4637

Gourlay, D., Heit, H. \& Caplan, Y. Urine Drug Testing in Clinical Practice: The Art and Science of Patient Care. California Academy of Family Physicians. Stamford, CT: PharmaCom Group, Inc., 2010.

Gourlay, D. \& Heit, H.A. (2010b). The Art and Science of Urine Drug Testing. Clin J Pain, Vol.26, No.4, pp.358,

Hall, A., Logan, J., Toblin, R., Kaplan, J., Kraner, J., Bixler, D., Crosby, A. \& Paulozzi, L. (2008). Patterns of Abuse among Unintentional Pharmaceutical Overdose Fatalities. JAMA, Vol.300, No.22, (December 2008), pp.2613-2620, ISSN 1538-3598

Hammett-Stabler, C. \& Webster, L. A Clinical Guide to Urine Drug Testing: Augmenting Pain Management and Enhancing Patient Care. University of Medicine and 
Dentistry of New Jersay - Center for Continuing and Outreach Education. Stamford, CT: PharmaCom Group, Inc, 2008.

Harmful Interactions: Mixing Alcohol with Medicines. National Institute on Alcohol Abuse and Alcoholism. Bethesda, MD: National Institutes of Health, 2007.

Hattab, E., Goldberger, B., Johannsen, L., Kindland, P., Ticino, F., Chronister, C. \& Bertholf, R. (2000). Modification of Screening Immunoassays to Detect Sub-Threshold Concentrations of Cocaine, Cannabinoids, and Opiates in Urine: Use for Detecting Maternal and Neonatal Drug Exposures. Annals of Clinical and Laboratory Science, Vol.31, No.1, (January 2000), pp.85-91, ISSN 1550-8080

Helander, A. \& Beck, O. (2005). Ethyl Sulfate: A Metabolite of Ethanol in Humans and a Potential Biomarker of Acute Alcohol Intake. Journal of Analytical Toxicology, Vol.29, No.5, (July-August 2005), pp.270-274, ISSN 1945-2403

Helander, A., Beck, O. \& Jones, A. (1996). Laboratory Testing for Recent Alcohol Consumption: Comparison of Ethanol, Methanol, and 5-Hydroxytryptophol. Clinical Chemistry, Vol.42, No.4, (April 1996), pp.618-624, ISSN 1530-8561

Heltsley, R., Zichterman, A., Black, D., Cawthon, B., Robert, T., Moser, F., Caplan, Y. \& Cone, E. (2010). Urine Drug Testing of Chronic Pain Patients. Ii. Prevalence Patterns of Prescription Opiates and Metabolites. Journal of Analytical Toxicology, Vol.34, No.1, (January-February 2010), pp.32-38, ISSN 1945-2403

Ives, T., Chelminski, P., Hammett-Stabler, C., Malone, R., Perhac, J., Potisek, N., Shilliday, B., DeWalt, D. \& Pignone, M. (2006). Predictors of Opioid Misuse in Patients with Chronic Pain: A Prospective Cohort Study. BMC Health Services Research, Vol.6, No.1, (April 2006), pp.46, ISSN 1472-6963

Jung, B. \& Reidenberg, M. (2007). Physicians Being Deceived. Pain Medicine, Vol.8, No.5, (July-August 2007), pp.433-437, ISSN 1526-4637

Katz, N., Sherburne, S., Beach, M., Rose, R., Vielguth, J., Bradley, J. \& Fanciullo, G. (2003). Behavioral Monitoring and Urine Toxicology Testing in Patients Receiving LongTerm Opioid Therapy. Anesthesia and Analgesia, Vol.97, No.4, (October 2003), pp.1097-1102, ISSN 1526-7598

Krausz, M., Degkwit, P., Haasen, C. \& Verthein, U. (1996). Opioid Addiction and Suicidality. Crisis, Vol.17, No.4, pp.175-181,

Kuehn, B.M. (2007). Opioid Prescriptions Soar: Increase in Legitimate Use as Well as Abuse. JAMA, Vol.297, No.3, pp.249-251, 0098-7484 1538-3598

Madras, B., Compton, W., Avula, D., Stegbauer, T., Stein, J. \& Clark, H. (2009). Screening, Brief Interventions, Referral to Treatment (Sbirt) for Illicit Drug and Alcohol Use at Multiple Healthcare Sites: Comparison at Intake and 6 Months Later. Drug and Alcohol Dependence, Vol.99, No.1-3, (January 2009), pp.280-295, ISSN 1879-0046

Manchikanti, L., Atluri, S., Trescot, A. \& Giordano, J. (2008). Monitoring Opioid Adherence in Chronic Pain Patients: Tools, Techniques, and Utility. Pain Physician, Vol.11, No.2, (March 2008), pp.S155-S180, ISSN 1533-3159

Manchikanti, L., Cash, K., Damron, K., Manchukonda, R., Pampati, V. \& McManus, C. (2006a). Controlled Substance Abuse and Illicit Drug Use in Chronic Pain Patients: An Evaluation of Multiple Variables. Pain Physician, Vol.9, No.3, (July 2006), pp.215-226, ISSN 1533-3159 
Manchikanti, L., Damron, K., McManus, C. \& Barnhill, R. (2004). Patterns of Illicit Drug Use and Opioid Abuse in Patients with Chronic Pain at Initial Evaluation: A Prospective, Observational Study. Pain Physician, Vol.7, No.4, (October 2004), pp.431-437, ISSN 1533-3159

Manchikanti, L., Malla, Y., Wargo, B., Cash, K., Pampati, V., Damron, K., McManus, C. \& Brandon, D. (2010). Protocol for Accuracy of Point of Care (Poc) or in-Office Urine Drug Testing (Immunoassay) in Chronic Pain Patients: A Prospective Analysis of Immunoassay and Liquid Chromatography Tandem Mass Spectometry (Lc/Ms/Ms). Pain Physician, Vol.13, No.1, (January 2010), pp.E1-E22, ISSN 15333159

Manchikanti, L., Manchukonda, R., Pampati, V., Damron, K., Brandon, D., Cash, K. \& McManus, C. (2006b). Does Random Urine Drug Testing Reduce Illicit Drug Use in Chronic Pain Patients Receiving Opioids? Pain Physician, Vol.9, No.2, (April 2006), pp.123-129, ISSN 1533-3159

Manchikanti, L., Manchukonda, R., Pampati, V. \& Damron, K.S. (2005). Evaluation of Abuse of Prescription and Illicit Drugs in Chronic Pain Patients Receiving Short-Acting (Hydrocodone) or Long-Acting (Methadone) Opioids. Pain Physician, Vol.8, No.3, pp.257-261,

Michna, E., Jamison, R., Pham, L., Ross, E., Janfaza, D., Nedeljkovic, S., Narang, S., Palombi, D. \& Wasan, A. (2007). Urine Toxicology Screening among Chronic Pain Patients on Opioid Therapy: Frequency and Predictability of Abnormal Findings. The Clinical Journal of Pain, Vol.23, No.2, (February 2007), pp.173-179, ISSN 1536-5409

Mikel, C., Almazan, P., West, R., Crews, B., Latyshev, S., Pesce, A. \& West, C. (2009). LcMs/Ms Extends the Range of Drug Analysis in Pain Patients. Therapeutic Drug Monitoring, Vol.31, No.6, (December 2009), pp.746-748, ISSN 1536-3694

Mikel, C., Pesce, A. \& West, C. (2010). A Tale of Two Drug Testing Technologies: Gc-Ms and Lc-Ms/Ms. Pain Physician, Vol.13, No.1, pp.91-92,

Mohsin, S., Yang, Y. \& Zumwalt, M. Quantitative Analysis of Opiates in Urine Using Rrht Lc/Ms/Ms. Santa Clara, CA: Agilent Technologies, Inc., 2007.

Nafziger, A. \& Bertino, J., Jr. (2009). Utility and Application of Urine Drug Testing in Chronic Pain Management with Opioids. The Clinical Journal of Pain, Vol.25, No.1, (January 2009), pp.73-79, ISSN 1536-5409

National Prescription Drug Threat Assesment. U.S. Department of Justice. Johnstown, PA: National Drug Intelligence Center, 2009.

National Survey on Drug Use and Health: Detailed Tables - Prevalence Estimates, Standard Errors, P Values, and Sample Sizes. Substance Abuse and Mental Health Services Administration. Rockville, MD: Department of Health and Human Services, 19952006.

Nucynta - Tapentadol. (2010). December 3, 2010, Available from: <www.nucynta.com>

Okie, S. (2010). A Flood of Opioids, a Rising Tide of Deaths. The New England Journal of Medicine, Vol.363, No.21, (November 2010), pp.1981-1985, ISSN 1533-4406

Olympus Au640 Product Information. Brea, CA: Beckman Coulter, Inc. Lab Systems and Routine Testing. 
Oyefeso, A., Ghodse, H., Clancy, C., Corkery, J. \& Goldfinch, R. (1999). Drug Abuse-Related Mortality: A Study of Teenage Addicts over a 20-Year Period. Social Psychiatry and Psychiatric Epidemiology, Vol.34, No.8, (August 1999), pp.437-441, ISSN 1433-9285

Pesce, A., Rosenthal, M., West, R., West, C., Crews, B., Mikel, C., Almazan, P. \& Latyshev, S. (2010a). An Evaluation of the Diagnostic Accuracy of Liquid ChromatographyTandem Mass Spectrometry Versus Immunoassay Drug Testing in Pain Patients. Pain Physician, Vol.13, No.3, pp.273-281,

Pesce, A., West, C., Rosenthal, M., West, R., Crews, B., Mikel, C., Almazan, P., Latyshev, S. \& Horn, P. (2010b). Marijuana Correlates with Use of Other Illicit Drugs in a Pain Patient Population. Pain Physician, Vol.13, No.3, pp.283-287,

Pesce, A., West, C., West, R., Crews, B., Mikel, C., Almazan, P., Latyshev, S., Rosenthal, M. \& Horn, P. (2010c). Reference Intervals: A Novel Approach to Detect Drug Abuse in a Pain Patient Population. Journal of Opioid Management, Vol.6, No.5, (SeptemberOctober 2010), pp.341-350, ISSN 1551-7489

Pesce, A., West, C., West, R., Crews, B., Mikel, C., Rosenthal, M., Almazan, P. \& Latyshev, S. (2011). Determination of Medication Cutoff Values in a Pain Patient Population. Journal of Opioid Management, Vol.In Press, (n.d.), ISSN 1551-7489

Principles of Drug Addiction Treatment: A Research-Based Guide. National Institue on Drug Abuse. Bethesda, MD: Department of Health and Human Services, 2009.

Reisfield, G., Salazar, E. \& Bertholf, R. (2007). Rational Use and Interpretation of Urine Drug Testing in Chronic Opioid Therapy. Annals of Clinical and Laboratory Science, Vol.37, No.4, (Autumn 2007), pp.301-314, ISSN 1550-8080

Rosano, T. \& Lin, J. (2008). Ethyl Glucuronide Excretion in Humans Following Oral Administration of and Dermal Exposure to Ethanol. Journal of Analytical Toxicology, Vol.32, No.8, (October 2008), pp.594-600, ISSN 1945-2403

Schmitt, G., Droenner, P., Skopp, G. \& Aderjan, R. (1997). Ethyl Glucuronide Concentration in Serum of Human Volunteers, Teetotalers, and Suspected Drinking Drivers. Journal of Forensic Sciences, Vol.42, No.6, (November 1997), pp.1099-1102, ISSN 15564029

Schuckman, H., Hazelett, S., Powell, C. \& Steer, S. (2008). A Validation of Self-Reported Substance Use with Biochemical Testing among Patients Presenting to the Emergency Department Seeking Treatment for Backache, Headache, and Toothache. Substance Use and Misuse, Vol.43, No.5, (n.d.), pp.589-595, ISSN 14339285

Siemens V-Twin Analyzer Product Information. Hermosa Beach, CA: Siemens Healthcare Diagnostic, Inc.

Siuzdak, G. (2006). The Expanding Role of Mass Spectrometry in Biotechnology (2nd ed.), MCC Press, San Diego, CA

Sobolevsky, T., Prasolov, I. \& Rodchenkov, G. (2010). Detection of Jwh-018 Metabolites in Smoking Mixture Post-Administration Urine. Forensic Science International, Vol.200, No.1-3, (July 2010), pp.141-147, ISSN 1872-6283

Stephanson, N., Dahl, H., A., H. \& Beck, O. (2002). Direct Quantification of Ethyl Glucuronide in Clinical Urine Samples by Liquid Chromatography-Mass 
Spectrometry. Therapeutic Drug Monitoring, Vol.24, No.5, (October 2002), pp.645651, ISSN 1536-3694

Thermo Fisher Mgc-240 Analyzer Product Information. Franklin, MA: Thermo Fisher Scientific.

Trescot, A., Boswell, M., Atluri, S., Hansen, H., Deer, T., Abdi, S., Jasper, J., Singh, V., Jordan, A., Johnson, B., Cicala, R., Dunbar, E., Helm, S., II, Varley, K., Suchdev, P., Swicegood, J., Calodney, A., Ogoke, B., Minore, W. \& Manchikanti, L. (2006). Opioid Guidelines in the Management of Chronic Non-Cancer Pain. Pain Physician, Vol.9, No.1, (January 2006), pp.1-40, ISSN 1533-3159

Vardakou, I., Pistos, C. \& Spiliopoulou, C. (2010). Spice Drugs as a New Trend: Mode of Action, Identification and Legislation. Toxicology Letters, Vol.197, No.3, (September 2010), pp.157-162, ISSN 1879-3169

Wall, R., Rehm, J., Fischer, B., Brands, B., Gliksman, L., Stewart, J., Medved, W. \& Blake, J. (2000). Social Costs of Untreated Opioid Dependence. Journal of Urban Health, Vol.77, No.4, (December 2000), pp.688-722, ISSN 1468-2869

Webster, L. \& Dove, B. (2007). Avoiding Opioid Abuse While Managing Pain: A Guide for Practitioners, Sunrise River Press, North Branch, MN

West, R., Crews, B., Mikel, C., Almazan, P., Latyshev, S., Pesce, A. \& West, C. (2009). Anomalous Observations of Codeine in Patients on Morphine. Therapeutic Drug Monitoring, Vol.31, No.6, (December 2009), pp.776-778, ISSN 1536-3694

West, R., Pesce, A., Crews, B., Mikel, C., Rosenthal, M., Almazan, P., Latyshev, S. \& West, C. (2011a). Determination of Illicit Drug Cutoff Values in a Pain Patient Population. Clinica Chimica Acta, Vol.In Press, (n.d.), ISSN 1873-3492

West, R., Pesce, A., Mikel, C., Rosenthal, M., Latyshev, S., Crews, B. \& Almazan, P. (2010a). Observations of Medication Compliance by Measurement of Urinary Drug Concentrations in a Pain Management Population. Journal of Opioid Management, Vol.6, No.4, (July-August 2010), pp.253-257, ISSN 1551-7489

West, R., Pesce, A., West, C., Crews, B., Mikel, C., Almazan, P., Rosenthal, M. \& Latyshev, S. (2010b). Comparison of Clonazepam Compliance by Measurement of Urinary Concentration by Immunoassay and Lc-Ms/Ms in Pain Management Population. Pain Physician, Vol.13, No.1, pp.71-78,

West, R., West, C., Crews, B., Almazan, P., Latyshev, S., Rosenthal, M., Pesce, A. \& Mikel, C. (2011b). Anomalous Observations of Hydrocodone in Patients on Oxycodone. Clinica Chimica Acta, Vol.412, No.1-2, (January 2011), pp.29-32, ISSN 1873-3492

Wingert, W. (1997). Lowering Cutoffs for Initial and Confirmation Testing for Cocaine and Marijuana: Large-Scale Study of Effects on the Rates of Drug-Positive Results. Clinical Chemistry, Vol.43, No.1, (January 1997), pp.100-103, ISSN 1530-8561

Wojcik, M. \& Hawthorne, J. (2007). Sensitivity of Commercial Ethyl Glucuronide (Etg) Testing in Screening for Alcohol Abstinence. Alcohol and Alcoholism, Vol.42, No.4, (July-August 2007), pp.317-320, ISSN 1464-3502

Wu, A.H.B. (2001). Urine Adulteration before Testing for Drugs of Abuse, In: The Clinical Toxicology Laboratory: Contemporary Practice of Poisoning Evaluation, L. C. Shaw, T. C. Kwong, T. G. Rosano, P. J. Orsolak, B. A. Wolf and B. Magnani, pp. 157-171, American Association for Clinical Chemistry, Inc., Washington, DC 
Wurst, F., Dresen, S., Allen, J., Wiesbeck, G., Graf, M. \& Weinmann, W. (2006). Ethyl Sulphate: A Direct Ethanol Metabolite Reflecting Recent Alcohol Consumption. Addiction, Vol.101, No.2, (February 2006), pp.204-211, ISSN 1360-0443

Wurst, F., Wiesbeck, G., Metzger, J., Weinmann, W. \& Graf, M. (2004). On Sensitivity, Specificity, and the Influence of Various Parameters on Ethyl Glucuronide Levels in Urine - Results from the Who/Isbra Study. Alcoholism, Clinical and Experimental Research, Vol.28, No.8, (August 2004), pp.1220-1228, ISSN 1530-0277 


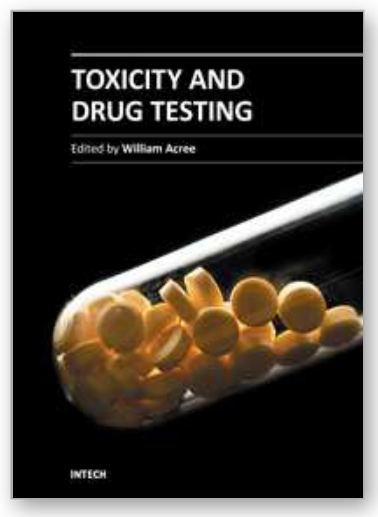

\author{
Toxicity and Drug Testing \\ Edited by Prof. Bill Acree
}

ISBN 978-953-51-0004-1

Hard cover, 528 pages

Publisher InTech

Published online 10, February, 2012

Published in print edition February, 2012

Modern drug design and testing involves experimental in vivo and in vitro measurement of the drug candidate's ADMET (adsorption, distribution, metabolism, elimination and toxicity) properties in the early stages of drug discovery. Only a small percentage of the proposed drug candidates receive government approval and reach the market place. Unfavorable pharmacokinetic properties, poor bioavailability and efficacy, low solubility, adverse side effects and toxicity concerns account for many of the drug failures encountered in the pharmaceutical industry. Authors from several countries have contributed chapters detailing regulatory policies, pharmaceutical concerns and clinical practices in their respective countries with the expectation that the open exchange of scientific results and ideas presented in this book will lead to improved pharmaceutical products.

\title{
How to reference
}

In order to correctly reference this scholarly work, feel free to copy and paste the following:

Amadeo Pesce, Cameron West, Kathy Egan-City and William Clarke (2012). Diagnostic Accuracy and Interpretation of Urine Drug Testing for Pain Patients: An Evidence-Based Approach, Toxicity and Drug Testing, Prof. Bill Acree (Ed.), ISBN: 978-953-51-0004-1, InTech, Available from: http://www.intechopen.com/books/toxicity-and-drug-testing/urine-drug-testing-in-pain-patients

\section{INTECH}

open science | open minds

\author{
InTech Europe \\ University Campus STeP Ri \\ Slavka Krautzeka 83/A \\ 51000 Rijeka, Croatia \\ Phone: +385 (51) 770447 \\ Fax: +385 (51) 686166 \\ www.intechopen.com
}

\author{
InTech China \\ Unit 405, Office Block, Hotel Equatorial Shanghai \\ No.65, Yan An Road (West), Shanghai, 200040, China \\ 中国上海市延安西路65号上海国际贵都大饭店办公楼 405 单元 \\ Phone: +86-21-62489820 \\ Fax: +86-21-62489821
}


(C) 2012 The Author(s). Licensee IntechOpen. This is an open access article distributed under the terms of the Creative Commons Attribution 3.0 License, which permits unrestricted use, distribution, and reproduction in any medium, provided the original work is properly cited. 